\title{
Elemental proxies for paleosalinity analysis
}

\author{
WeI WeI' AND ThOMAS J ALGeO² \\ ${ }^{1}$ Faculty of Earth Resources, China University of \\ Geosciences (Wuhan), Wuhan 430074, China \\ 2 Department of Geology, University of Cincinnati, \\ Cincinnati, Ohio 45221-0013, U.S.A.
}

Salinity is a fundamental property of watermasses that is useful in paleoenvironmental and paleoecological studies, yet the theory of application of geochemical proxies to paleosalinity reconstruction is underdeveloped. Here, we explore the use of three elemental ratios for paleosalinity reconstruction: boron/gallium (B/Ga), strontium/barium ( $\mathrm{Sr} / \mathrm{Ba})$, and sulfur/total organic carbon $(\mathrm{S} / \mathrm{TOC})$ ratios. We compiled a large set of modern aqueous and sedimentary chemical data representing a range of salinity facies (i.e., freshwater, brackish, marine) in order to test the relationships of these proxies to ambient watermass salinity and to determine their viability for paleosalinity analysis. Sediment data were limited to fine-grained siliciclastic units (muds/shales/mudstones) without significant carbonate content, in which the elements of interest were mainly acquired through adsorption of dissolved species, forging a connection between elemental proxy values and watermass chemistry. In modern systems, watermass salinity is correlated with these proxies, yielding $r$ of +0.99 and +0.76 for aqueous and sediment $\mathrm{B} / \mathrm{Ga},+0.66$ and +0.54 for aqueous and sediment $\mathrm{Sr} / \mathrm{Ba}$, and +0.98 for aqueous sulfate and +0.66 for sediment S/TOC (all significant at $p(\alpha)<$ 0.01 ). These relationships establish the basis for use of these elemental ratios as paleosalinity proxies. Elemental crossplots permitted estimation of approximate salinity thresholds for each proxy: (1) $\mathrm{B} / \mathrm{Ga}$ is $<3$ in freshwater, 3-6 in brackish, and $>6$ in marine facies; (2) $\mathrm{Sr} / \mathrm{Ba}$ is $<0.2$ in freshwater, 0.2-0.5 in brackish, and >0.5 in marine facies; and (3) S/TOC is $<0.1$ in freshwater and $>0.1$ in brackish and marine facies. S/TOC did not discriminate effectively between brackish and marine facies, probably because microbial sulfate reduction (MSR) is generally $\mathrm{C}_{\mathrm{og}}$-limited rather than sulfate-limited in both facies. The accuracies of these thresholds for prediction of the salinity facies of sediments are $\sim 88 \%$ for $\mathrm{B} / \mathrm{Ga}, \sim 66 \%$ for $\mathrm{Sr} / \mathrm{Ba}$, and $\sim 91 \%$ for $\mathrm{S} / \mathrm{TOC}$. Although the $\mathrm{Sr} / \mathrm{Ba}$ proxy is slightly less robust owing to difficulty in removing all carbonate $\mathrm{Sr}$ influence and/or to greater mobility of $\mathrm{Sr}$ and $\mathrm{Ba}$ in the burial environment, we strongly advocate use of multiple proxies in order to support paleosalinity interpretations. The application of these proxies are also illustrated in two ancient studies, to test the validation of these proxies. 